\title{
Prehospital arterial hypercapnia in acute heart failure is associated with admission to acute care units and emergency room length of stay: a retrospective cohort study
}

Mathias Fabre ${ }^{1 * \dagger} \mathbb{D}$, Christophe A. Fehlmann ${ }^{1 \dagger}$, Birgit Gartner ${ }^{1}$, Catherine G. Zimmermann-Ivoll ${ }^{2}$, Florian Rey ${ }^{3}$, François Sarasin ${ }^{1}$ and Laurent Suppan ${ }^{1}$

\begin{abstract}
Background: Acute Heart Failure (AHF) is a common condition that often presents with acute respiratory distress and requires urgent medical evaluation and treatment. Arterial hypercapnia is common in AHF and has been associated with a higher rate of intubation and non-invasive ventilation in the Emergency Room (ER), but its prognostic value has never been studied in the prehospital setting.

Methods: A retrospective study was performed on the charts of all patients taken care of by a physician-staffed prehospital mobile unit between June 2016 and September 2019 in Geneva. After approval by the ethics committee, charts were screened to identify all adult patients with a diagnosis of AHF in whom a prehospital arterial blood gas (ABG) sample was drawn. The main predictor was prehospital hypercapnia. The primary outcome was the admission rate in an acute care unit (ACU, composite of intensive care and high-dependency units). Secondary outcomes were ER length of stay (LOS), orientation from ER (intensive care unit, high-dependency unit, general ward, discharge home), intubation rate at $24 \mathrm{~h}$, hospital LOS and hospital mortality.

Results: A total of 106 patients with a diagnosis of AHF were analysed. Hypercapnia was found in 61 (58\%) patients and vital signs were more severely altered in this group. The overall ACU admission rate was $48 \%$, with a statistically significant difference between hypercapnic and non-hypercapnic patients (59\% vs 33\%, $p=0.009$ ). ER LOS was shorter in hypercapnic patients (5.4 h vs $8.9 \mathrm{~h}, p=0.016)$.

Conclusions: There is a significant association between prehospital arterial hypercapnia, acute care unit admission, and ER LOS in AHF patients.
\end{abstract}

Keywords: Acute heart failure, Arterial blood gas, Prehospital

\footnotetext{
* Correspondence: mathias.fabre@hcuge.ch

${ }^{\dagger}$ Mathias Fabre and Christophe A. Fehlmann contributed equally to this work.

'Division of Emergency, Department of Anaesthesiology, Clinical

Pharmacology, Intensive Care and Emergency Medicine, Geneva University

Hospitals and Faculty of Medicine, Rue Gabrielle-Perret-Gentil 4, CH-1205

Geneva, Switzerland

Full list of author information is available at the end of the article
}

(c) The Author(s). 2021 Open Access This article is licensed under a Creative Commons Attribution 4.0 International License, which permits use, sharing, adaptation, distribution and reproduction in any medium or format, as long as you give appropriate credit to the original author(s) and the source, provide a link to the Creative Commons licence, and indicate if changes were made. The images or other third party material in this article are included in the article's Creative Commons licence, unless indicated otherwise in a credit line to the material. If material is not included in the article's Creative Commons licence and your intended use is not permitted by statutory regulation or exceeds the permitted use, you will need to obtain permission directly from the copyright holder. To view a copy of this licence, visit http://creativecommons.org/licenses/by/4.0/ The Creative Commons Public Domain Dedication waiver (http://creativecommons.org/publicdomain/zero/1.0/) applies to the data made available in this article, unless otherwise stated in a credit line to the data. 


\section{Background}

Acute Heart Failure (AHF) is a common but lifethreatening condition with a high mortality. It often manifests by acute respiratory distress and requires urgent medical evaluation and management [1, 2]. Classical treatment includes use of vasodilators, diuretics and oxygen, as well as positive end-expiratory pressure (PEEP), with or without pressure support (PS), in case of severe AHF [3-11]. In the prehospital setting, application of PEEP, whether by use of continuous positive airway pressure (CPAP) or of noninvasive ventilation (NIV), is associated with an improvement in vital parameters and a reduction in both endotracheal intubation (ETI) and intensive care unit (ICU) admission rates [1216]. Common negative prognostic markers for AHF include hypotension on admission, advanced age and polymorbidity, as well as an ischemic etiology [2].

Arterial blood gas (ABG) analysis has been shown to increase the quality of treatment in the prehospital setting [17]. Hypercapnia is a common finding in patients admitted to ICU because of AHF [18, 19]. Though Konishi et al. have shown that hypercapnia is associated with increased rates of both NIV and ETI in the intrahospital setting [18], its predictive value in the prehospital environment is not known. The goal of this study was to evaluate the association between prehospital hypercapnia and admission to acute care units (ACU), including ICU and high-dependency units (HDU).

\section{Methods}

\section{Study design}

This was a retrospective cohort study, based on data obtained from an electronic charts review, exploring the association between hypercapnia in the prehospital field and admission to an ACU. The study protocol was approved by the institutional ethics committee of Geneva, Switzerland (project ID 2019-01559). Patient consent was waived by this committee.

\section{Setting}

This study was carried out using data from the prehospital medical mobile unit (called SMUR for Service Mobile d'Urgence et de Réanimation) of the Geneva University Hospitals in Switzerland, the detailed organization of which has previously been described [12]. Briefly, the prehospital emergency medical response in Geneva consists of three levels of increasing expertise (advanced life support ambulance, medical mobile unit, senior emergency-medicine certified physician). The SMUR is staffed by a paramedic and a physician and is called upon according to specific dispatch protocols or if the first responding paramedics request it. Severe respiratory distress is among the criteria used to dispatch this unit. In addition to providing specific medical skills and knowledge, the SMUR can initiate NIV in the field well before arrival in the emergency room (ER). A Hamilton T1 ventilator (Hamilton Medical AG, Bonaduz, Switzerland) has been part of the standard SMUR equipment since 2013. ABG analysis has been possible since 2016 thanks to a portative i-STAT point-of-care blood analyzer (Abbott Point of Care inc., Princeton, New Jersey, USA). The indication for drawing an ABG sample in the field is left to the physician's appreciation but is strongly suggested whenever NIV treatment is initiated. In order to avoid unnecessary delays, SMUR physicians are only allowed one single attempt on the radial artery in at most $1 \mathrm{~min}$. There is no specific data available regarding the timing of ABG analysis, but SMUR physicians almost always begin by administering oxygen and often initiate NIV or other life-saving measure before drawing blood for analysis.

\section{Participants}

Electronic charts of all patients for whom an intervention took place between 01.07.2016 and 30.09.2019 were screened for inclusion. There are only 126 different diagnoses that can be coded in the SMUR's prehospital medical charts, and only two relate to AHF: "acute pulmonary edema" (APE) and "heart failure" (HF). All patients 18 years or older with any of these two diagnoses were initially included. Exclusion criteria were absence of an acute HF (lack of an acute component described in the report), cardiac arrest upon rescuers' arrival, presence of a mixed or unclear diagnosis (such as a concomitant acute chronic obstructive pulmonary disease exacerbation), secondary transfer from another hospital or emergency structure, and limitation of care regarding ACU admission. Finally, patients for whom prehospital arterial ABG could not be obtained were also excluded.

\section{Data collection}

Validated, indexed data of all the patients included in the analysis was imported to a REDCap (Vanderbilt University, Nashville, Tennessee, USA) electronic case report form (CRF). The first author (MF) was in charge of the full data collection, including all the manual data extraction required to complete the CRF. Any doubt was lifted by a consensus between MF and two of the other authors (CAF and LS).

\section{Exposure}

The main predictor was prehospital hypercapnia, defined as $\mathrm{PaCO}_{2}$ equal or higher to $6 \mathrm{kPa}(45 \mathrm{mmHg})$. According to our institutional guidelines, the accuracy of the iSTAT analyzer was regularly assessed by internal and external quality controls (QC). Internal QC were tested at multiple levels on each lot number at delivery for 
precision evaluation. External QC were performed at least 7 times per year for accuracy evaluation. QC of the 'analyzer' itself was achieved by use of an electronic check cartridge twice per year for electronics evaluation.

\section{Outcomes}

The primary outcome was ACU admission, a composite outcome of admission to either HDU or ICU. Secondary outcomes were ER length of stay (LOS), orientation from ER (ICU, HDU, general and internal medicine wards, or discharge home), ETI (on field or in the first $24 \mathrm{~h}$ ), hospital LOS and hospital mortality.

Week-end interventions were those performed on Saturdays and Sundays. Night interventions occurred between $7 \mathrm{PM}$ and $7 \mathrm{AM}$. Length of intervention was the time elapsed between the arrival on site and the arrival at hospital. In-hospital ABG was retained if made in the first hour in emergency. Others blood samples were retained if realized in first $6 \mathrm{~h}$ in ER.

\section{Statistical analysis}

As this was an exploratory study, no sample size calculation was performed. Groups were compared by Student's $t$-test, the Mann-Whitney Wilcoxon test or the chisquared test as appropriate. Results are expressed as mean \pm standard deviation or absolute number and relative percentage. When appropriate, 95\% confidence interval $(95 \mathrm{CI})$ are also reported. A $p$-value below 0.05 was considered significant. A single subgroup analysis was performed according to whether there was a correction of hypercapnia upon arrival in the ER. Missing data were reported as such and patients excluded from analyses if necessary (no imputation was made). Statistical analysis was performed using STATA version 14 (Stata Corporation, College Station, Texas, USA).

\section{Results}

A total of $17^{\prime} 997$ patients were taken care of by the SMUR during the study period, among whom 972 met the inclusion criteria. We then excluded 866 patients to finally include 106 patients (10.9\%) in the analysis (Fig. 1).

Table 1 summarizes patients' characteristics. Patients with $(n=61,58 \%)$ and without $(n=45,42 \%)$ hypercapnia were similar regarding personal history except for chronic hypertension and likely coronary heart disease and diabetes. Prehospital vital signs as well as Glasgow coma scale (GCS) were more severely altered in the hypercapnia group. Hypercapnic patients were more often put under NIV, which was set at significantly higher PS settings. Data were missing mainly for GCS (18\%) and ER hypercapnia (19\%).

The global ACU admission rate was 48\% (51/106), with a significant difference between patients with and without hypercapnia $(59.0 \%$ vs $33.3 \%, p=0.009)$ (Table 2). This difference was likely due to a higher

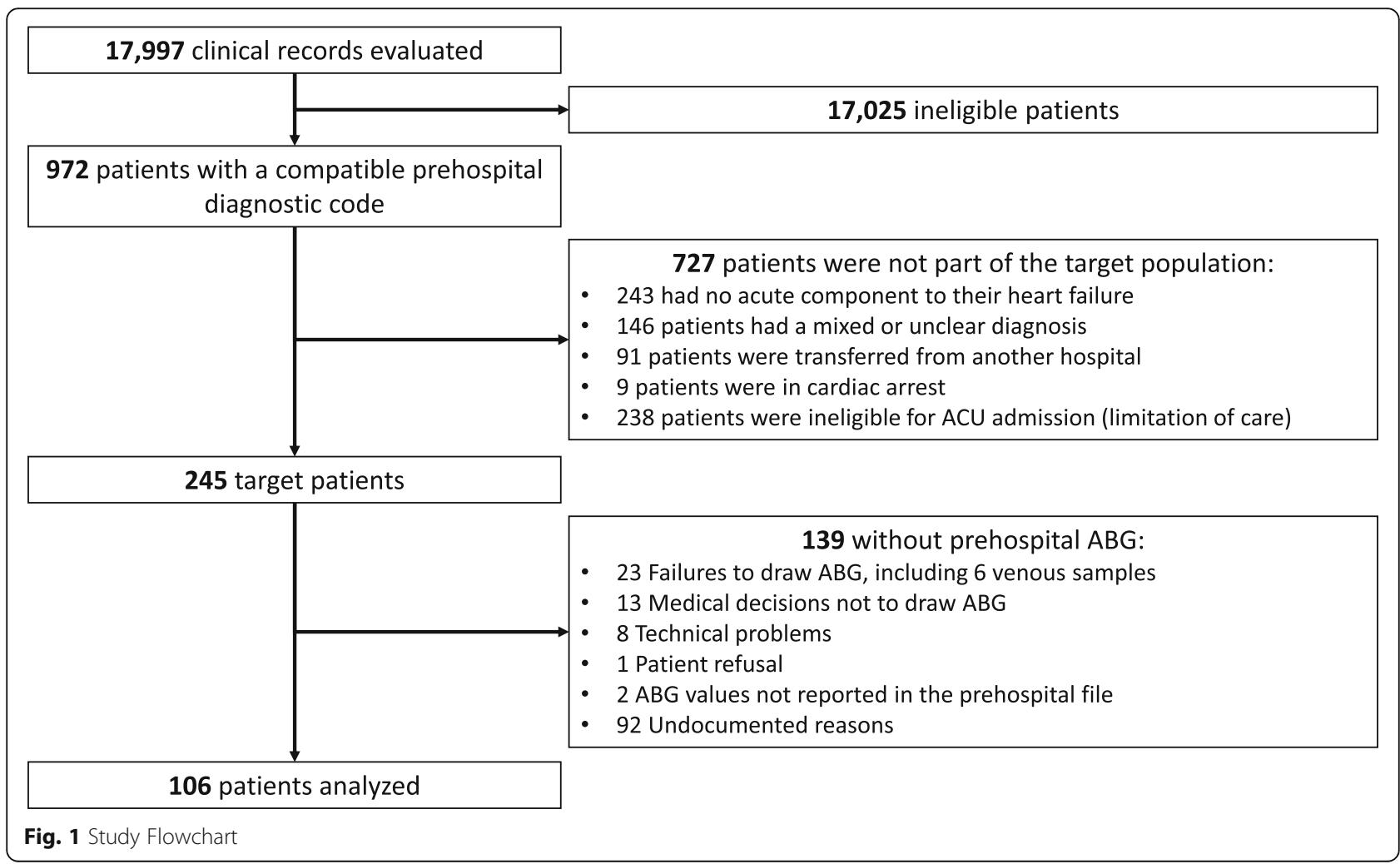


Table 1 Patient's characteristics ${ }^{\mathrm{a}}$

\begin{tabular}{|c|c|c|c|}
\hline & No prehospital hypercapnia $(n=45)$ & Prehospital Hypercapnia $(n=61)$ & $p$-value \\
\hline Age (y) & $79.2 \pm 8.0$ & $79.8 \pm 8.1$ & 0.719 \\
\hline $\operatorname{Sex}(f)-n(\%)$ & $21(46.7)$ & $37(61.0)$ & 0.153 \\
\hline Week-end intervention - n (\%) & $16(36.4)$ & $13(22.4)$ & 0.122 \\
\hline Night intervention - n (\%) & $26(57.8)$ & $37(61.0)$ & 0.765 \\
\hline Length of intervention (m) & $41 \pm 10$ & $42 \pm 12$ & 0.701 \\
\hline \multicolumn{4}{|l|}{ Personal history - n (\%) } \\
\hline Hypertension & $37(82.2)$ & $58(95.1)$ & 0.032 \\
\hline Coronary heart disease & $19(42.2)$ & $17(27.9)$ & 0.123 \\
\hline Atrial fibrillation & $22(48.9)$ & $23(37.7)$ & 0.250 \\
\hline Pacemaker & $11(24.4)$ & $9(14.8)$ & 0.208 \\
\hline Active cancer & $2(4.4)$ & $3(4.9)$ & 0.909 \\
\hline Chronic obstructive pulmonary disease & $8(17.8)$ & $10(16.4)$ & 0.851 \\
\hline Diabetes mellitus & $13(28.9)$ & $26(42.6)$ & 0.147 \\
\hline Chronic renal failure & $18(40.0)$ & $29(47.5)$ & 0.480 \\
\hline Prior hospitalisation for heart failure & $15(33.3)$ & $26(42.6)$ & 0.562 \\
\hline Tobacco & $7(15.6)$ & $9(14.8)$ & 0.982 \\
\hline \multicolumn{4}{|l|}{ Prehospital vital signs } \\
\hline Heart rate $(1 / \mathrm{min})$ & $104 \pm 20$ & $114 \pm 20$ & 0.013 \\
\hline Systolic blood pressure (mmHg) & $174 \pm 31$ & $189 \pm 29$ & 0.013 \\
\hline Diastolic blood pressure $(\mathrm{mmHg})$ & $94 \pm 16$ & $112 \pm 18$ & $<0.001$ \\
\hline Respiratory rate (1/min) & $34 \pm 9$ & $38 \pm 7$ & 0.019 \\
\hline Oxygen saturation (\%) & $86 \pm 9$ & $83 \pm 13$ & 0.194 \\
\hline Glasgow Coma Scale - n (\%) & & & 0.018 \\
\hline$<15$ & $3(6.7)$ & $17(27.9)$ & \\
\hline 15 & $33(73.3)$ & $32(52.5)$ & \\
\hline Missing values & $9(20.0)$ & $12(19.7)$ & \\
\hline Prehospital $\mathrm{PaCO}_{2}(\mathrm{kPa})$ & $5.0 \pm 0.6$ & $7.7 \pm 1.6$ & $<0.001$ \\
\hline Prehospital pH & $7.38 \pm 0.06$ & $7.23 \pm 0.11$ & $<0.001$ \\
\hline Prehospital NIV & $34(75.6)$ & $59(96.7)$ & 0.001 \\
\hline PEEP $(m m H g)$ & $6.0 \pm 1.7$ & $6.4 \pm 2.0$ & 0.369 \\
\hline$P S$ & $8.1 \pm 1.7$ & $9.4 \pm 2.1$ & 0.006 \\
\hline Hospital hypercapnia - n (\%) & & & 0.001 \\
\hline No hypercapnia & $29(64.4)$ & $24(39.3)$ & \\
\hline Hypercapnia & $5(11.1)$ & $28(45.9)$ & \\
\hline Missing value & $11(24.4)$ & $9(14.8)$ & \\
\hline \multicolumn{4}{|l|}{ Emergency room work-up } \\
\hline Haemoglobin $(g / d l)$ & $130 \pm 23$ & $126 \pm 20$ & 0.225 \\
\hline Serum creatinine $(\mu \mathrm{mol} / \mathrm{l})$ & $128 \pm 75$ & $152 \pm 147$ & 0.285 \\
\hline Pro-B-type natriuretic peptide (ng/l) & $6225 \pm 7548$ & $6699 \pm 9665$ & 0.809 \\
\hline
\end{tabular}

admission rate in ICU for hypercapnic patients. Hypercapnic patients who did not correct their $\mathrm{PaCO}_{2}$ upon ER arrival were not more likely to be admitted to an $\mathrm{ACU}$ than those who did correct their $\mathrm{PaCO}_{2}$ (respectively $71.4 \%$ versus $58 \%, p=0.323$ ). The change in $\mathrm{PaCO}_{2}$ in hypercapnic patients between prehospital and ER ABG was not associated with ACU admission either (respectively $-1.26 \mathrm{kPa}$ for patients admitted to an 
Table 2 Outcomes ${ }^{a}$

\begin{tabular}{llll}
\hline & $\begin{array}{l}\text { All } \\
(\boldsymbol{n}=\mathbf{1 0 6})\end{array}$ & $\begin{array}{l}\text { No prehospital hypercapnia } \\
(\boldsymbol{n}=\mathbf{4 5})\end{array}$ & $\begin{array}{l}\text { Prehospital Hypercapnia } \\
(\boldsymbol{n}=\mathbf{6 1})\end{array}$ \\
\hline $\begin{array}{l}\text { Primary outcome } \\
\text { ACU admission }-\mathrm{n}(\%)\end{array}$ & $51(48.1)$ & $15(33.3)$ & $36(59.0)$ \\
$\begin{array}{l}\text { Secondary outcomes } \\
\text { Emergency LOS (h) }\end{array}$ & $6.9 \pm 6.5$ & $8.9 \pm 9.0$ & $5.4 \pm 2.9$ \\
Orientation from ER - n (\%) & & & \\
ICU admission & $25(23.6)$ & $4(8.9)$ & $21(34.4)$ \\
HDU admission & $26(24.5)$ & $11(24.4)$ & $15(24.6)$ \\
Ward & $51(48.1)$ & $26(57.8)$ & $25(41.0)$ \\
Discharge directly from ER & $4(3.8)$ & $4(8.9)$ & 0.009 \\
ETI - n (\%) & $5(4.7)$ & $0(0.0)$ & $5(8.2)$ \\
Hospital LOS (d) & $13.1 \pm 9.4$ & $11.9 \pm 6.8$ & $14.1 \pm 10.7$ \\
Hospital mortality $-\mathrm{n}(\%)$ & $5(4.7)$ & $1(2.2)$ & $4(6.6)$ \\
\hline
\end{tabular}

a Plus-minus values are means \pm standard deviation, Percentages may not total 100 due to rounding

ACU versus $-1.13 \mathrm{kPa}$ for those who were not, $p=$ 0.715). Emergency room LOS was significantly shorter in hypercapnic patients $(5.4 \pm 2.9 \mathrm{~h}$ versus $8.9 \pm 9.0 \mathrm{~h}$, $p=0.016)$. They also had higher intubation rate at $24 \mathrm{~h}$, hospital LOS and mortality, albeit not significantly so.

\section{Discussion}

Our study shows a significant association between prehospital hypercapnia and ACU admission. This result seems mainly explained by the difference in ICU admissions between the two groups.

In our study, the prevalence of hypercapnia was higher than in most others (58\% vs $33.7 \%$ in Konishi's study [18], for example). To explain this difference, two hypotheses can be put forward. The first is related to the fact that we report prehospital values as opposed to other studies, which usually report in-hospital values. Therefore, an improvement consecutive to prehospital treatment before ER arrival cannot be ruled out in these settings. Indeed, our results show that almost $40 \%$ of patients with prehospital hypercapnia were normocapnic upon arrival in the ER. Another hypothesis is that prehospital physicians were more prone to performing ABG analyses in critically ill patients, thereby inducing a selection bias.

The difference between hypercapnic and nonhypercapnic patients regarding ACU admissions is probably best explained by the fact that hypercapnic patients seemed to be in a worse clinical state. These patients were indeed more tachycardic, more severely hypertensive, had lower GCS scores and higher respiratory rates. They also had a higher ETI rate at $24 \mathrm{~h}$. The association between hypercapnia and worse clinical state is not fully elucidated, and the pathophysiological mechanisms leading to hypercapnia are not fully understood. It has been theorized that gas exchange might be impaired by the development of interstitial edema [20], and muscle fatigue, which leads to hypoventilation, certainly contributes to the increase in $\mathrm{PaCO}_{2}$ [21]. This latter effect probably best explains the link between hypercapnia and ETI, which was significant despite the limited sample size and the almost systematic use of NIV in hypercapnic patients. Indeed, prehospital NIV has been shown to significantly decrease the need for prehospital ETI [12].

In our study, hypercapnia was associated with a significantly lower LOS in the ER. Though it can hardly be assumed that hypercapnia alone was responsible for this time reduction in ER, one might argue that in-hospital orientation for patients with worse clinical state was more straightforward and could therefore account for this finding. Whether the ER physicians took prehospital ABG results into account could not be ascertained owing to the design of this study, and a prospective evaluation should be performed to determine the potential causality link. Should a link between early evaluation of $\mathrm{ABG}$ in the prehospital phase and ACU admission be proven, fast-tracks similar to those used for stroke or myocardial infarction could be considered [22, 23]. Such fast-tracks have been shown to shorten the delay to initiation of optimal in-hospital treatment, and might also decrease the strain on the ER and the waiting time of other patients [24].

Different limitations must be acknowledged. The small study sample did not have sufficient power to draw conclusions regarding mortality or to adjust our results for potential confounders. Moreover, potentially valuable data, such as usual medications, frailty parameters, or left ventricular function could not be obtained, further limiting the interpretation of our findings. Furthermore, though a clear relationship between ACU admission and 
prehospital hypercapnia has been found, such a relationship does not necessarily imply causality. One last limitation is the retrospective design of this study, as diagnosis of heart failure can differ from one physician to another. Nevertheless, as our prehospital chart only allows the use of a limited and standardized list of diagnoses, such differences might have been mitigated.

Despite these elements, the good quality of patient's data can be highlighted, and is mainly linked to the review of electronically recorded charts the use of which lessens memorization bias. Another strong point is that, as prehospital hypercapnia has to our knowledge never been studied in AHF, this work shows new elements that could improve patient orientation in the ER. Prospective studies would be needed to better describe the role of prehospital hypercapnia in AHF.

\section{Conclusion}

In conclusion, this study shows a significant association between prehospital arterial hypercapnia, ACU admissions, ER LOS and ETI in patients with AHF. Prospective studies should now be carried out to confirm these results before prehospital ABG can be recommended on a routine.

\section{Abbreviations}

ABG: Arterial Blood Gas; ACU: Acute Care Unit; AHF: Acute Heart Failure; APE: Acute pulmonary Edema; CRF: Case Report Form; CPAP: Continuous Positive Airway Pressure; ER: Emergency Room; ETI: Endotracheal Intubation; GCS: Glasgow Coma Scale; HDU: High-dependency Unit; HF: Heart Failure; ICU: Intensive Care Unit; LOS: Length of Stay; NIV: Non-Invasive Ventilation; PEEP: Positive End-Expiratory Pressure; PS: Pressure Support; QC: Quality ControlSMURService Mobile d'Urgences et de Réanimation

\section{Acknowledgements}

\section{not applicable.}

\section{Authors' contributions}

conceptualization, M.F., C.A.F, B.G., F.S., L.S.; formal analysis, C.A.F and L.S.; investigation, M.F.; data curation: C.A.F.; writing-original draft, M.F., C.A.F.; writing-review and editing, M.F., C.A.F., B.G., C.Z.I, F.R., F.S., L.S.; supervision: F.S., L.S.; Project administration, L.S. All authors have read and agreed to the submitted version of the manuscript.

\section{Funding}

This research receive no external funding.

\section{Availability of data and materials}

The datasets used and analysed during the current study are available from the corresponding author on reasonable request.

\section{Ethics approval and consent to participate}

The study was conducted at Geneva University Hospitals in accordance with Good Clinical Practice (Declaration of Helsinki 2002). This study was approved on 20.08.2019 by the institutional ethics committee of Geneva, Switzerland (Project ID 2019-01559). Patient consent was waived by this committee.

\section{Consent for publication}

Not applicable.

\section{Competing interests}

The authors declare no competing interests.

\section{Author details}

'Division of Emergency, Department of Anaesthesiology, Clinical Pharmacology, Intensive Care and Emergency Medicine, Geneva University Hospitals and Faculty of Medicine, Rue Gabrielle-Perret-Gentil 4, CH-1205 Geneva, Switzerland. ${ }^{2}$ Division of Medicine Laboratory, Department of Diagnostics, Geneva University Hospitals and Faculty of Medicine, Geneva, Switzerland. ${ }^{3}$ Division of Cardiology, Department of medicine, Geneva University Hospitals and Faculty of Medicine, Geneva, Switzerland.

Received: 3 August 2020 Accepted: 20 January 2021

Published online: 26 January 2021

\section{References}

1. Ponikowski P, Voors A, Anker S, Bueno H, Cleland J, Coats A, Falk V, et al. 2016 ESC guidelines for the diagnosis and treatment of acute and chronic heart failure. Eur Soc Cardiol. 2016;37:2129-200. https://doi.org/10.1016/j.rec. 2016.10.015.

2. Tubaro M, Price S, Vrints C. Acute heart failure: epidemiology, classification and pathophysiology. In: ESC Textbook of Intensive and Acute Cardiovascular Care; 2014. https://doi.org/10.1016/s1261-694x(14)70679-0.

3. Potts JM. Noninvasive positive pressure ventilation - effect on mortality in acute cardiogenic pulmonary edema: a pragmatic meta-analysis. Pol Arch Med Wewn. 2009;1 19(6):349-53.

4. Cabrini L, Landoni G, Oriani A, Plumari VP, Nobile L, Greco M, et al. Noninvasive ventilation and survival in acute care settings: a comprehensive systematic review and metaanalysis of randomized controlled trials. Crit Care Med. 2015;43(4):880-8. https://doi.org/10.1097/CCM. 0000000000000819

5. Masip J, Roque M. Noninvasive Ventilation in Acute Cardiogenic Pulmonary Edema: Systematic review and meta-analysis. J Am Med Assoc. 2005;294(24). https://doi.org/10.1001/jama.294.24.3124.

6. Mariani J, MacChia A, Belziti C, Deabreu M, Gagliardi J, Doval H, et al. Noninvasive ventilation in acute cardiogenic pulmonary edema: a metaanalysis of randomized controlled trials. J Card Fail. 2011;17(10):850-9. https://doi.org/10.1016/j.cardfail.2011.05.010.

7. Vital F, Ladeira M, Atallah A. Non-invasive positive pressure ventilation ( CPAP or bilevel NPPV ) for cardiogenic pulmonary oedema ( review ). Cochrane Database Syst Rev. 2013;5. https://doi.org/10.1002/14651858. CD005351.pub3.www.cochranelibrary.com.

8. Berbenetz N, Wang Y, Brown J, Vital FMR. Non-invasive positive pressure ventilation (CPAP or bilevel NPPV) for cardiogenic pulmonary oedema. Cochrane Database Syst Rev. 2019;5(5):CD005351. https://doi.org/10.1002/ 14651858.CD005351.pub3.

9. Weng C-L, Zhao Y-T, Liu Q-H, Fu C-S, Sun F, Ma Y-L, et al. Meta-analysis: noninvasive ventilation in acute cardiogenic pulmonary edema. Ann Intern Med. 2010;152(9):590. https://doi.org/10.7326/0003-4819-152-9-20100504000009.

10. Gray A, Goodacre S, Newby DE, Masson M, Sampson F, Nicholl J. Noninvasive ventilation in acute cardiogenic pulmonary edema. N Engl J Med. 2008;359(2):142-51. https://doi.org/10.1056/NEJMoa0707992.

11. Mosesso VN, Dunford J, Blackwell T, Griswell JK. Prehospital therapy for acute congestive heart failure: state of the art. Prehospital Emergency Care: In; 2003. https://doi.org/10.1080/10903120390937049.

12. Gartner BA, Fehlmann C, Suppan L, Niquille M, Rutschmann OT, Sarasin F. Effect of noninvasive ventilation on intubation risk in prehospital patients with acute cardiogenic pulmonary edema: a retrospective study. Eur J Emerg Med. 2019. https://doi.org/10.1097/MEJ.0000000000000616.

13. Weitz G, Struck J, Zonak A, Balnus S, Perras B, Dodt C. Prehospital noninvasive pressure support ventilation for acute cardiogenic pulmonary edema. Eur J Emerg Med. 2007;14(5):276-9. https://doi.org/10.1097/MEJ. Ob013e32826fb377.

14. Simpson PM, Bendall JC. Prehospital non-invasive ventilation for acute cardiogenic pulmonary oedema: an evidence-based review. Emerg Med J. 2011;28(7):609-12. https://doi.org/10.1136/emj.2010.092296.

15. Williams TA, Finn J, Perkins GD, Jacobs IG. Prehospital continuous positive airway pressure for acute respiratory failure: a systematic review and meta-analysis. Prehospital Emerg Care. 2013. https://doi.org/10.3109/10903127.2012.749967.

16. Taylor DMD, Bernard SA, Masci K, MacBean CE, Kennedy MP. Prehospital noninvasive ventilation: a viable treatment option in the urban setting. Prehospital Emerg Care. 2008. https://doi.org/10.1080/10903120701710389. 
17. Zwisler ST, Zincuk Y, Bering CB, Zincuk A, Nybo M, Mikkelsen S. Diagnostic value of prehospital arterial blood gas measurements - a randomised controlled trial. Scand J Trauma Resusc Emerg Med. 2019. https://doi.org/10. 1186/s13049-019-0612-8.

18. Konishi M, Akiyama E, Suzuki H, Iwahashi N, Maejima N, Tsukahara K, et al. Hypercapnia in patients with acute heart failure. ESC Hear Fail. 2015;2(1):129. https://doi.org/10.1002/ehf2.12023.

19. Lazzeri C, Gensini GF, Picariello C, Attanà P, Mattesini A, Chiostri M, et al. Acidemia in severe acute cardiogenic pulmonary edema treated with noninvasive pressure support ventilation: a single-center experience. J Cardiovasc Med. 2015;16(9):610-5. https://doi.org/10.2459/JCM. 0000000000000079.

20. Schlosshan D, Elliott M. Prognostic indicators in patients presenting with acute cardiogenic pulmonary edema treated with CPAP: It's not the acid that matters, it's back to basics. Crit Care. 2010;14(6):14-5. https://doi.org/10. $1186 /$ cc932.

21. Valipour A, Cozzarini W, Burghuber OC. Non-invasive pressure support ventilation in patients with respiratory failure due to severe acute cardiogenic pulmonary edema. Respiration. 2004. https://doi.org/10.1159/ 0000766755.

22. Grosgurin O, Plojoux J, Keller P-F, Niquille M, N'koulou R, Mach F, et al. Prehospital emergency physician activation of interventional cardiology team reduces door-to-balloon time in ST-elevation myocardial infarction. Swiss Med Wkly. 2010;140:228-32 smw-12927.

23. Herlitz J, Wireklintsundström B, Bång A, Berglund A, Svensson L, Blomstrand C. Early identification and delay to treatment in myocardial infarction and stroke: differences and similarities. Scand J Trauma Resusc Emerg Med. 2010; 18:48. https://doi.org/10.1186/1757-7241-18-48.

24. Oredsson S, Jonsson H, Rognes J, Lind L, Göransson KE, Ehrenberg A, et al. A systematic review of triage-related interventions to improve patient flow in emergency departments. Scand J Trauma Resusc Emerg Med. 2011;19:43. https://doi.org/10.1186/1757-7241-19-43

\section{Publisher's Note}

Springer Nature remains neutral with regard to jurisdictional claims in published maps and institutional affiliations.

Ready to submit your research? Choose BMC and benefit from:

- fast, convenient online submission

- thorough peer review by experienced researchers in your field

- rapid publication on acceptance

- support for research data, including large and complex data types

- gold Open Access which fosters wider collaboration and increased citations

- maximum visibility for your research: over $100 \mathrm{M}$ website views per year

At $\mathrm{BMC}$, research is always in progress.

Learn more biomedcentral.com/submissions 